\title{
Research on Photosynthetic Leguminous Forage in the Karst Rocky Desertification Regions of Southwestern China
}

\author{
Kangning Xiong ${ }^{1,2 *}$, Yongkuan Chi ${ }^{1,2}$, Xiaoyun Shen ${ }^{1}$ \\ ${ }^{1}$ School of Karst Science, Guizhou Normal University, \\ P. O. Box 550001, 116 Baoshan North Road, Guiyang, Guizhou, P.R. China \\ ${ }^{2}$ State Engineering Technology Institute for Karst Desertification Control, \\ P. O. Box 550001, 116 Baoshan North Road, Guiyang, Guizhou, P.R. China
}

Received: 19 November 2016

Accepted: 13 March 2017

\begin{abstract}
The photosynthetic characteristics of three kinds of leguminous forages were studied in a karst rocky desertification area of Guizhou using the photosynthetic apparatus on sunny days. The results showed that the curves of annual diurnal variation of the net photosynthetic rate and transpiration rate on three kinds of experiment forges showed different variation trends that were mainly related to the experimental materials. They showed that there were significant differences in the net photosynthetic and transpiration rates of different grasses, and also in photosynthetic physiology changes of different seasons. Through the annual photosynthetic physiological studies among Trifolium repens, Trifolium pretense, Medicago sativa, and other forage legumes can be concluded that the highest annual average net photosynthetic rate of leguminous forage was Medicago sativa followed by Trifolium repens, and Trifolium pretense was the lowest; the highest transpiration rate was Trifolium pretense followed by Trifolium repens, and the lowest was Medicago sativa, with little differences of this three leguminous forage. The highest photosynthetic efficiency and the lowest transpiration rate make the water use efficiency of Medicago sativa the highest, followed by Trifolium repens, and the lowest was Trifolium pretense. In most months, Trifolium repens, Trifolium pretense, and Medicago sativa were sensitive to high photosynthetic active radiation and high temperature, so taking a dormant form with closing their pores to reduce its water loss and material consumption. The primary productivity of grassland depends largely on water use efficiency. When establishing artificial grassland in the karst rocky desertification area we need to consider the net photosynthetic rate, transpiration rate, and water use efficiency, and take measures to use different kinds of forage, which not only reduce water loss but also improve water use efficiency and ease drought and water shortage in rocky desertification areas. From considering the overall perspective of annual photosynthetic physiological characteristics,
\end{abstract}

*e-mail: xiongkn@163.com 
Medicago sativa is more suitable than Trifolium repens and Trifolium pretense for the habitat conditions in light-moderate karst rocky desertification areas.

Keywords: southwestern China, rocky desertification, Leguminosae forage, photosynthetic characteristics

\section{Introduction}

The southwestern China karst area, which centers on Guizhou and covers more than $550,000 \mathrm{~km}^{2}$, is the largest and the most intense area in karst distributions of the world. Rocky desertification is the most serious geological and ecological disaster in this region. It has seriously hindered the improvement of the local ecological environment and social and economic development [1-3]. Due to the limitation of karst environmental factors such as shallow soil layer, poor soil, and lack of surface water, it is difficult to develop traditional planting industry in the karst area. According to some relevant research, planting artificial pasture develops animal husbandry, which is one of the most economical methods with ecological benefits in the rocky desertification region [4].

The study of ecological effects, social and economic benefits, symbiosis of forest and grass and economic forest, and the introduction and cultivation of forage construction in karst areas has received wide attention [4-6]. Screening for suitable pasture in karst areas, especially in rocky desertification regions, is of great significance to study the interaction of karst ecosystems. The karst ecosystem is an ecosystem constrained by karst environment [7]. Vegetation in karst areas is typical of xerophytic, lithogenic, and calcic types [7-8]. Tropical and subtropical rain in the karst area is very rich due to the special binary structure of the karst ecosystem. Ecological environment is often arid, forming a special karst-arid environment. Plants growing in the karst area often show karst plant-specific xerophilicity [7,9]. A karst ecological environment with high temperature, drought, uneven rainfall, and other features, therefore, is considered that screening the forage plants suitable for the growth of a karst environment should take full account of the characteristics of regional environmental conditions [10]. Because the structural characteristics and photosynthetic characteristics of plant leaves are closely related to their environments, so different habitats will show differently adaptive characteristics and mechanisms [11-14]. The mechanism of interaction between plants and environmental factors and their adaptability to biotopes can be reflected by plant photosynthetic characteristics and leaf traits and their relationships [15-16]. Therefore, the study of plant photosynthetic characteristics and structural characteristics under certain environmental conditions is an important content of plant adaptability research [17-19]. A great deal of research has been done on the photosynthetic characteristics of forage grasses at home and abroad [20-23]. It is an initial stage to study photosynthetic characteristics of forage grasses in karst rocky desertification areas with special biotopes. Photosynthesis is a physiological process that is sensitive to changes in the environment [24], and is closely related to eco-environment conditions. Studies on plant photosynthetic characteristics not only understand the differences in light utilization characteristics among different plants and their physiology mechanism, but also reveal the effective methods of ecologically adaptive mechanisms of different plants [25].

This paper studied the physiological and ecological indexes of net photosynthetic rate, transpiration rate, and water use efficiency of three leguminous grasses planted in light and moderate karst rocky desertification areas in order to select those most suitable for legume forage establishment that can provide a scientific basis in the karst rocky desertification area.

\section{Material and Methods}

\section{Study Area}

The study was conducted as part of the national "13th Five-year Plan" with light-moderate rocky desertification of karst plateau-mountain in Salaxi Comprehensive Demonstration Area of Bijie. The demonstration is located in the town of Salaxi, Qixingguan District, Bijie City, Guizhou Province (E 10502'01" $105^{\circ} 08^{\prime} 09^{\prime \prime}$, $\left.\mathrm{N} 27^{\circ} 11^{\prime} 36^{\prime \prime} \sim 27^{\circ} 16 ' 51^{\prime \prime}\right)$, with an average elevation of $1,800 \mathrm{~m}$. It belongs to subtropical monsoon humid climate, annual average temperature is about $12^{\circ} \mathrm{C}$, the frost-free period is 245 days (with 1,360 hours of annual sunshine duration), and $984.4 \mathrm{~mm}$ of annual average rainfall (with more than $80 \%$ of the rainfall concentrated in June to September). It is typical karst plateau-mountain with potential-light rocky desertification area. The main soil type is yellow soil. The original vegetation is dominated by Cyclobalanopsis glauca, Pyracantha fortuneana, and Rhododendron simsii. Around the local slopes and residential areas are scattered Pinus yunnanensis [26].

\section{Materials}

\section{Experiment Materials}

The research materials were leguminous Trifolium repens, Medicago sativa, Trifolium pretense, and Cichorium intybus purchased from Guizhou Shennong Seed Company. Sowing them on 9 April 2013, all of them used strip sowing, and spreading $750 \mathrm{~kg} / \mathrm{hm}^{2}$ 0base fertilizer before sowing, each partition reserved $0.5 \mathrm{~m}$ district, then removing the weeds at any time according to the situation of the weeds.

Trifolium repens is widely planted in southern China, and likes the warm cool and humid climate such as 
Bijie. The suitable climate for growing is $19 \sim 24^{\circ} \mathrm{C}$ and good growth with annual rainfall of $600-800 \mathrm{~mm}$. It is resistant to shade, cold, acid, moisture, not saline alkali, and its drought resistance is weak. Trifolium pratense is also widely grown in China, and likes a cool and humid climate. It is resistant to moisture, not drought, and hot. Summer is difficult in the hot dry valley of Huajiang. Known as "the king of pasture," Medicago sativa is one of the most importance leguminous forages and is widely planted.

\section{Experimental Study Patterns}

The photosynthetic experiments in fields were conducted on sunny days in April, July, and October 2014. Choosing the sample plots of similar density and coverage (cover degree: 90\%), measured with the quadrats of similar tiller and branches, and then measured with the blades from the same part (from the upper third leaves). Three healthy plants were randomly selected from each of three trial materials, five leaves were measured, three times repeated, then we took the average value. Selecting 8:00, $10: 00,12: 00,14: 00,16: 00,18: 00$ from 8:00 to 18:00, and 19:00 was added in July because of the longer sunshine hours, so there were seven measuring time-points. We used the Lcpro+ portable photosynthetic measuring instrument made by ADC Bio-scientific company in UK, and set the red and blue light source leaf chamber to test the net photosynthetic rate $\left(\mathrm{P}_{\mathrm{n}}, \mu \mathrm{molCO}{ }_{2} \cdot \mathrm{m}^{-2} \cdot \mathrm{s}^{-1}\right)$, transpiration rate $\left(\mathrm{T}_{\mathrm{r}}, \mathrm{mmolH}_{2} \mathrm{O} \cdot \mathrm{m}^{-2} \cdot \mathrm{s}^{-1}\right)$, stomatal conductance of $\mathrm{CO}_{2}$ $\left(\mathrm{G}_{\mathrm{s}}, \mathrm{molH} \mathrm{H}_{2} \mathrm{O} \cdot \mathrm{m}^{-2} \cdot \mathrm{s}^{-1}\right)$, intercellular $\mathrm{CO}_{2}$ concentration $\left(\mathrm{C}_{\mathrm{i}}\right.$, $\left.\mu \mathrm{mol} \cdot \mathrm{mol}^{-1}\right)$, air temperature $\left(\mathrm{T},{ }^{\circ} \mathrm{C}\right)$, photosynthetic active radiation $\left(\mathrm{PAR}, \mu \mathrm{mol} \cdot \mathrm{m}^{-2} \cdot \mathrm{s}^{-1}\right.$ ), and other indexes. Water use efficiency is WUE $=\mathrm{Pn} / \mathrm{Tr}\left(\mu \mathrm{molCO}_{2} \cdot \mathrm{mmol}^{-1} \mathrm{H}_{2} \mathrm{O}\right)$. OriginPro 9.0 was used to conduct data statistics and make figures, and IBM SPSS 20.0 was used to conduct statistical analysis.

\section{Results and Discussion}

\section{The Characteristics of Annual Diurnal Variation on Main Environmental Indicators}

From Fig. 1a) we can see that the daily variations curve of photosynthetic active radiation in July was always in the upper of the other two months, the lowest in autumn of October, and the middle in spring of April. The maximums of photosynthetic active radiation all appeared at 12:00 and all exceed $2,000 \mu \mathrm{mol} \cdot \mathrm{m}^{-2} \cdot \mathrm{s}^{-1}$, while the minimum was less than $100 \mu \mathrm{mol} \cdot \mathrm{m}^{-2} \cdot \mathrm{s}^{-1}$.

From Fig. 1b), the highest temperature in the experimental field was in July, the lowest in October, and the middle in April. The atmospheric temperatures at noon all exceeded $40^{\circ} \mathrm{C}$ in July and April. The temperature difference between morning and evening was large in the autumn, while it was relatively small in the spring and summer.

We can see changes of atmospheric pressure in the experimental field from Fig. 1c). The fall was controlled by high pressure, which has a more prevailing wind, downdrafts and sunny weather, and the air pressure is higher. Therefore, the highest air pressure was in October, the lowest in July, and the middle in April. The diurnal variation curve of October was significantly higher than the other two seasons. The difference between autumn and the other two seasons was about 1,000 $\mathrm{Pa}$ in a day, while the diurnal variation in a season was not obvious.

\section{The Characteristics of Annual Diurnal Variation on the Net Photosynthetic Rate}

The net photosynthetic rate is one of the important physiological indexes of the forage. April is the early flowering period of most forages, the period for blooming and seeding, the assimilational capacity and growing

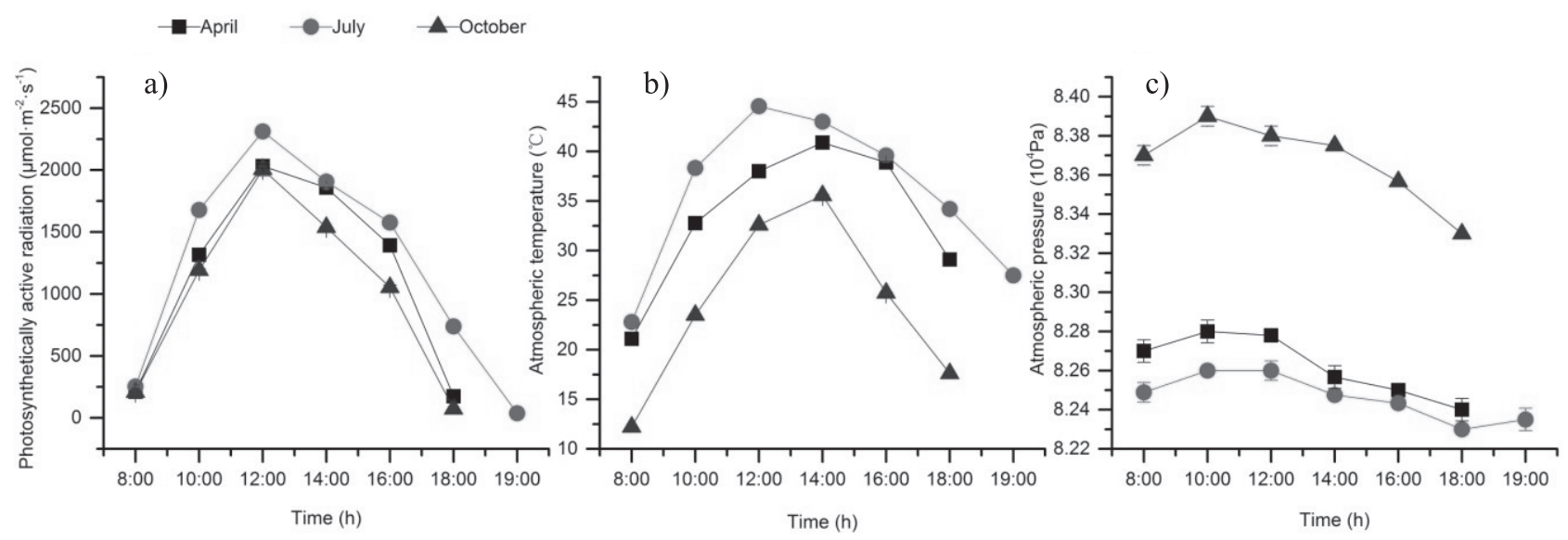

Fig. 1. Environmental parameters: a) Photosynthetic active radiation, b) Atmospheric temperature, c) Atmospheric pressure. 
Table 1 . The daily mean value of $P_{n}, T$, WUE, $G_{s}$, and $C_{i}$ on the forages.

\begin{tabular}{|c|c|c|c|c|c|}
\hline Species & $\begin{array}{c}\mathrm{P}_{\mathrm{n}} \\
/ \mu \mathrm{molCO}_{2} \mathrm{~m}^{-2} \mathrm{~s}^{-1}\end{array}$ & $\begin{array}{c}\mathrm{T}_{\mathrm{r}} \\
/ \mathrm{mmolH}_{2} \mathrm{Om}^{-2} \mathrm{~s}^{-1}\end{array}$ & $\begin{array}{c}\text { WUE } \\
/ \mu \mathrm{molOO}_{2} \mathrm{mmol}^{-1}\end{array}$ & $\begin{array}{c}\mathrm{G}_{\mathrm{s}} \\
/ \mathrm{molH}_{2} \mathrm{Om}^{-2} \mathrm{~s}^{-1}\end{array}$ & $\begin{array}{c}\mathrm{C}_{\mathrm{i}} \\
/ \mu \mathrm{molmol}^{-1}\end{array}$ \\
\hline Trifolium repens (Apr.) & $11.65 \pm 5.85$ & $4.95 \pm 2.31$ & $2.46 \pm 0.68$ & $0.21 \pm 0.13$ & $230.41 \pm 63.00$ \\
\hline Trifolium repens (Jul.) & $6.97 \pm 3.26$ & $4.64 \pm 1.91$ & $1.52 \pm 0.65$ & $0.31 \pm 0.30$ & $259.06 \pm 82.67$ \\
\hline Trifolium repens (Oct.) & $6.55 \pm 3.94$ & $3.33 \pm 2.33$ & $2.02 \pm 0.70$ & $0.62 \pm 0.90$ & $291.54 \pm 71.53$ \\
\hline Trifolium pratense (Apr.) & $7.09 \pm 3.76$ & $4.10 \pm 1.63$ & $1.73 \pm 0.65$ & $0.16 \pm 0.08$ & $258.94 \pm 57.25$ \\
\hline Trifolium pratense (Jul.) & $5.56 \pm 2.86$ & $4.66 \pm 1.78$ & $1.20 \pm 0.54$ & $0.28 \pm 0.17$ & $287.10 \pm 66.73$ \\
\hline Trifolium pratense (Oct.) & $7.24 \pm 4.13$ & $4.51 \pm 2.44$ & $1.82 \pm 0.97$ & $0.35 \pm 0.25$ & $304.82 \pm 38.04$ \\
\hline Medicago sativa (Apr.) & $9.71 \pm 5.68$ & $4.88 \pm 2.23$ & $1.98 \pm 0.66$ & $0.25 \pm 0.17$ & $256.69 \pm 63.09$ \\
\hline Medicago sativa (Jul.) & $9.49 \pm 5.56$ & $4.54 \pm 1.89$ & $2.03 \pm 1.14$ & $0.34 \pm 0.18$ & $259.33 \pm 93.61$ \\
\hline Medicago sativa (Oct.) & $6.46 \pm 3.57$ & $3.35 \pm 1.56$ & $2.31 \pm 1.69$ & $0.55 \pm 0.49$ & $317.52 \pm 37.25$ \\
\hline
\end{tabular}

power was the most vigorous, and the leaf photosynthetic capacity was the strongest in this month (Table 1, Figs 2a-c). Because of an environment with strong light and high temperature and the plants' productive phase, the leaf photosynthetic capacity was declining in midsummer of July. As the pasture will enter into the withering period in October, its photosynthetic capacity decreased gradually except at more appropriate temperatures.

As we can see from Fig. 2a) and Table 1, the net photosynthetic rate of Trifolium repens was the highest in April, followed by July, and the lowest was in October. In April, the net photosynthetic rate showed a peak value at 10:00, the secondary peak value appeared at 16:00, the phenomenon of midday depression of photosynthesis occurred at 12:00, but it was less obvious. The photosynthetic curve was relatively standard in July, the peak values occurred at 10:00 and 18:00, and it appeared midday depression of photosynthesis at 14:00. In October, the midday depression of photosynthesis was not obvious, and the net photosynthetic rate before 14:00 was significantly higher than subsequent measurement times.

From Fig. 2b), the obvious midday depression of photosynthesis did not appear in April and July except October. In April the apparent photosynthetic peak value appeared at 10:00 and then it declined all the time. The insignificant peak values appeared at 10:00, 14:00, and 18:00, and micro valley values appeared at 12:00 and 16:00 in July. The phenomenon of midday depression of photosynthesis was very obvious in October, when there were peak values at 10:00 and 16:00 and there was significant midday depression of photosynthesis at 14:00.

We can see from Fig. 2c) that the peak values of net photosynthetic rate of Medicago sativa appeared at 10:00, and then it declined all the time in April. The curve presented an inverted parabola-shape and the maximum value appeared at 14:00 in July. The curve of net photosynthetic rate was relatively obvious in October, the peak value appeared at 10:00 and 16:00, while the midday depression of photosynthesis occurred at 14:00.
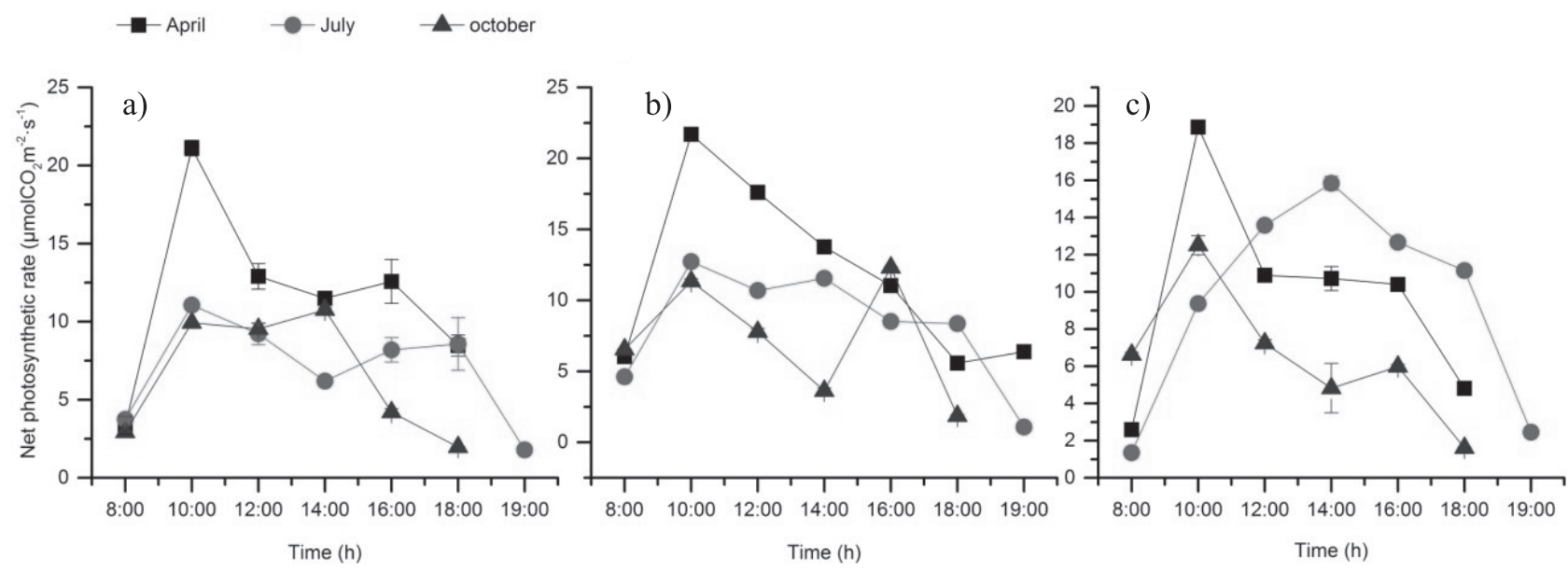

Fig. 2. The characteristics of annual diurnal variation on the net photosynthetic rate. a) Photosynthetic active radiation, b) Atmospheric temperature, c) Atmospheric pressure. 


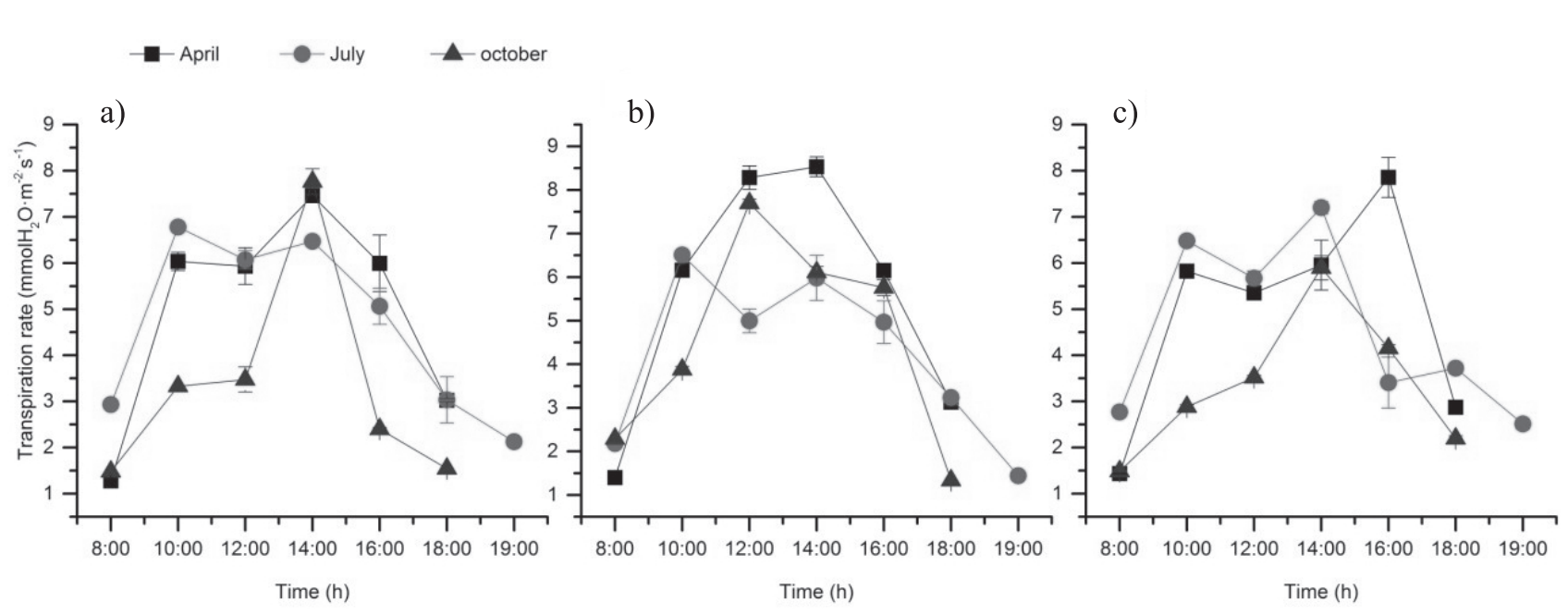

Fig. 3. The characteristics of annual diurnal variation on the transpiration rate. a) Photosynthetic active radiation, b) Atmospheric temperature, c) Atmospheric pressure.

\section{The Characteristics of Annual Diurnal Variation on Transpiration Rate}

April is the formation period of flower buds for pasture. The synthesis of buds needs a lot of water, therefore the capability of transpiration and transport is strong in April. Affected by high temperature and high illumination in summer, the transpiration of pasture is always high. While compared to autumn, plant vitality is declining and transpiration rate is decreasing.

As can be seen from Fig. 3a) and Table1, the highest transpiration rate of Trifolium repens was in April, followed by July and October. The maximum values of the transpiration rate in April and October all appeared at 14:00, but the maximum value of the transpiration rate in July appeared at 10:00 this moment. Compared with three curves, the relative change between April and July was small, with larger variations in October.

From Fig. 3b) we can see that the transpiration curve of Trifolium pratense presented inverted parabola in April, risen from 8:00 and reaching the maximum at 14:00. In July, the peak values of transpiration appeared at 10:00 and 14:00, and the valley value at 12:00. The peak value was more prominent in October, and the variation of the curve was more remarkable than in April.

We can see from Fig. 3c) the secondary maximum of Medicago sativa appeared at 10:00 in April and July, and the valley value at 12:00, while the maximum in April was at 16:00 and July was at 14:00. Overall, the transpiration curve in July move left a time point compared to April. The transpiration curve in October showed a single peak curve and the maximum appeared at 14:00.

\section{The Characteristics of Annual Diurnal Variation on Water Use Efficiency}

Water use efficiency is an important index to evaluate the strength of plant operation, and the efficiency of assimilation, drought resistance, and saving water. Water use efficiency can reflect the relationship of forages between

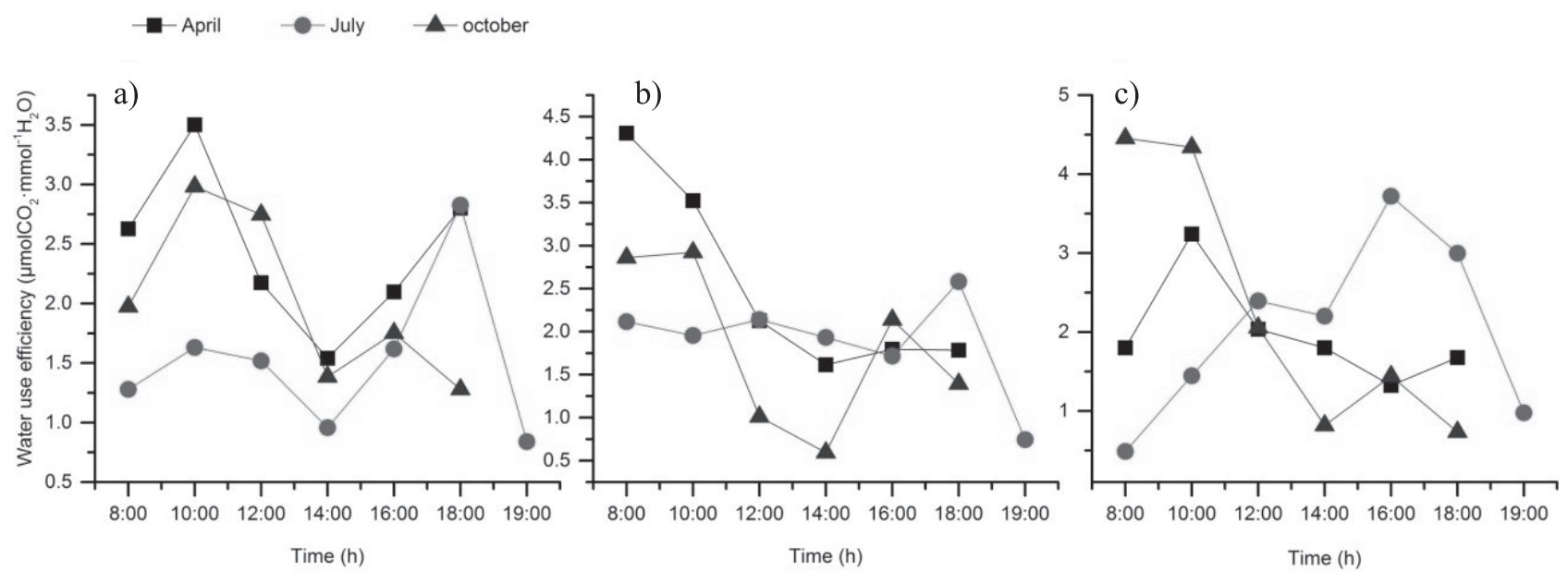

Fig. 4. The characteristics of annual diurnal variation on water use efficiency. a) Photosynthetic active radiation, b) Atmospheric temperature, c) Atmospheric pressure. 


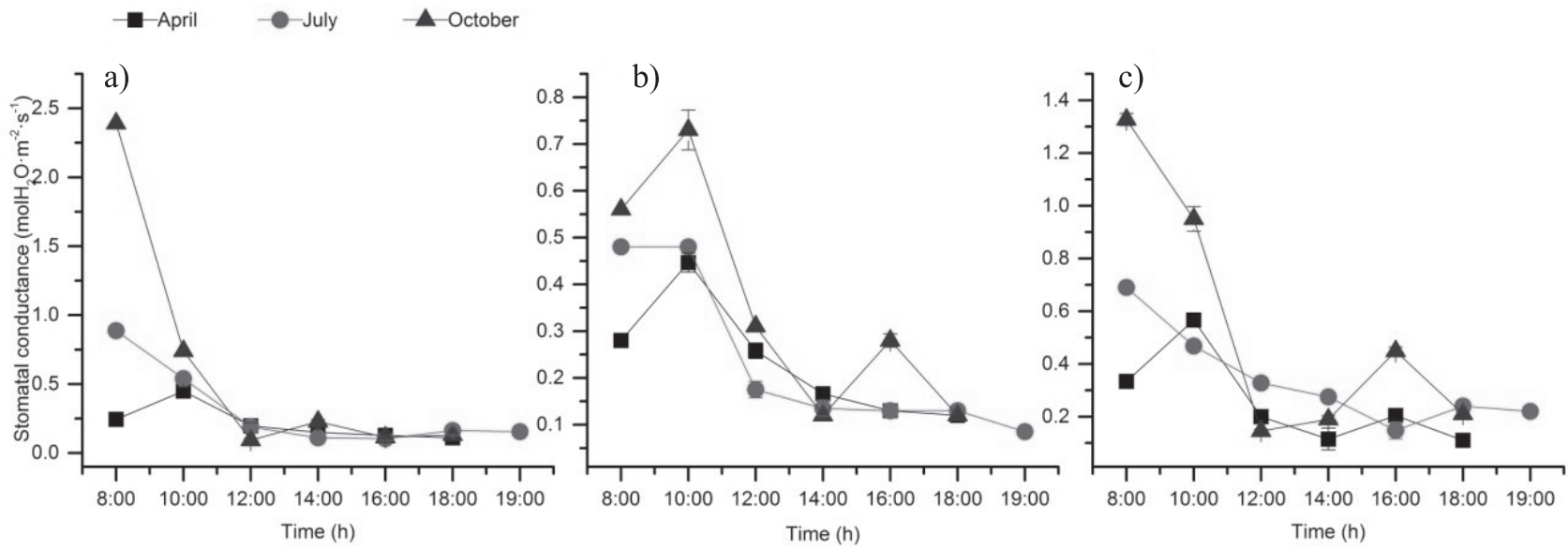

Fig. 5. The characteristics of annual diurnal variation on stomatal conductance. a) Photosynthetic active radiation, b) Atmospheric temperature, c) Atmospheric pressure.

photoassimilation on absorbing $\mathrm{CO}_{2}$ and transpiration on water consumption, which was mainly affected by the net photosynthetic rate and transpiration rate.

From Fig. 4a) and Table 1 we can see that the curve of water use efficiency of Trifolium repens appeared in two peaks at 10:00 and 18:00 in April, the valley value at 14:00, and it was on the upper when compared with the other two months. The inconspicuous peak in July appeared at 18:00. In addition, the maximum in October was at 10:00, the secondary maximum was at 16:00, and valley value was at 14:00.

As can be seen from Fig. 4b), the curve of water use efficiency of Trifolium pratense in April was basically declined except for a less obvious valley value that occurred at 14:00. The curve of July was gentle and a less obvious peak occurred at 12:00. The maximum values of curve of water use efficiency in October were at 10:00 and $16: 00$, the valley value was at 14:00, and the curve was in a position with a relatively low level.

From Fig. 4c), the water use efficiency of Medicago sativa in April was decreased from 8:00 to 14:00, and an inconspicuous peak was at 16:00. The curve change in July was gentle. In October there appeared two peaks at 10:00 and 16:00, and the valley value at 14:00.

\section{The Characteristics of Annual Diurnal Variation on Stomatal Conductance}

The stoma is the main channel for gas exchange between the plant leaves and the outside world. The diffused gases through the stoma are $\mathrm{O}_{2}, \mathrm{CO}_{2}$, and water vapor. The plants conduct photosynthesis under light, through the stoma to absorb $\mathrm{CO}_{2}$, so the stoma must be patulous. However, the stomatal opening also inevitably causes the transpiration. The stoma can adjust the size of their opening according to the change of environmental conditions, thus making the plants get the most $\mathrm{CO}_{2}$ under the condition of the least loss of water. The size of the stomatal opening has a direct effect on transpiration.
From Fig. 5a) the stomatal conductance of Trifolium repens with little difference in three measured months except for 8:00, and the stomatal conductance before 8:00 in October was higher than April and July.

Fig. 5b) shows, at 8:00-12:00, the that the stomatal conductance of Trifolium pratense in October was the highest. All the peak values appeared at 10:00, and there was a downward trend in the following (a secondary peak appeared at 16:00 in October).

Similarly, we can see from Fig. 5c) that the stomatal conductance of Medicago sativa in October was higher than the other two months except for 12:00-14:00. The change of stomatal conductance was small in April and July, which was much lower than in October.

\section{The Characteristics of Annual Diurnal Variation on Intercellular $\mathrm{CO}_{2}$ Concentration}

$\mathrm{CO}_{2}$ is the raw material of plants for conducting photosynthesis and making organics. The content of $\mathrm{CO}_{2}$ in the atmosphere has a direct effect on the photosynthesis of herbage. The higher intercellular $\mathrm{CO}_{2}$ concentration of the forage, the smaller $\mathrm{CO}_{2}$ concentration difference inside and outside the stomatal; the less $\mathrm{CO}_{2}$ absorbed by the stoma, the lower photosynthetic rate of the forage.

From Fig. 6a), the peak values of intercellular $\mathrm{CO}_{2}$ concentration of Trifolium repens all occurred at 8:00 and 18:00 (19:00), and the lowest values appeared at 16:00 in April and July, and at 12:00 in October.

As can be seen from Fig. 6b), the difference of intercellular $\mathrm{CO}_{2}$ concentration of Trifolium pratense was not large in April and July. The intercellular $\mathrm{CO}_{2}$ concentration in October was higher than the other two experimental periods, with all the peak values appearing at 8:00 and 18:00 (19:00).

Fig. 6c) showed the peak values of intercellular $\mathrm{CO}_{2}$ concentration of Medicago sativa appearing at 8:00 and 18:00 (19:00). The minimum values in April, July, and October occurred at 14:00, 16:00, and 12:00, respectively. 


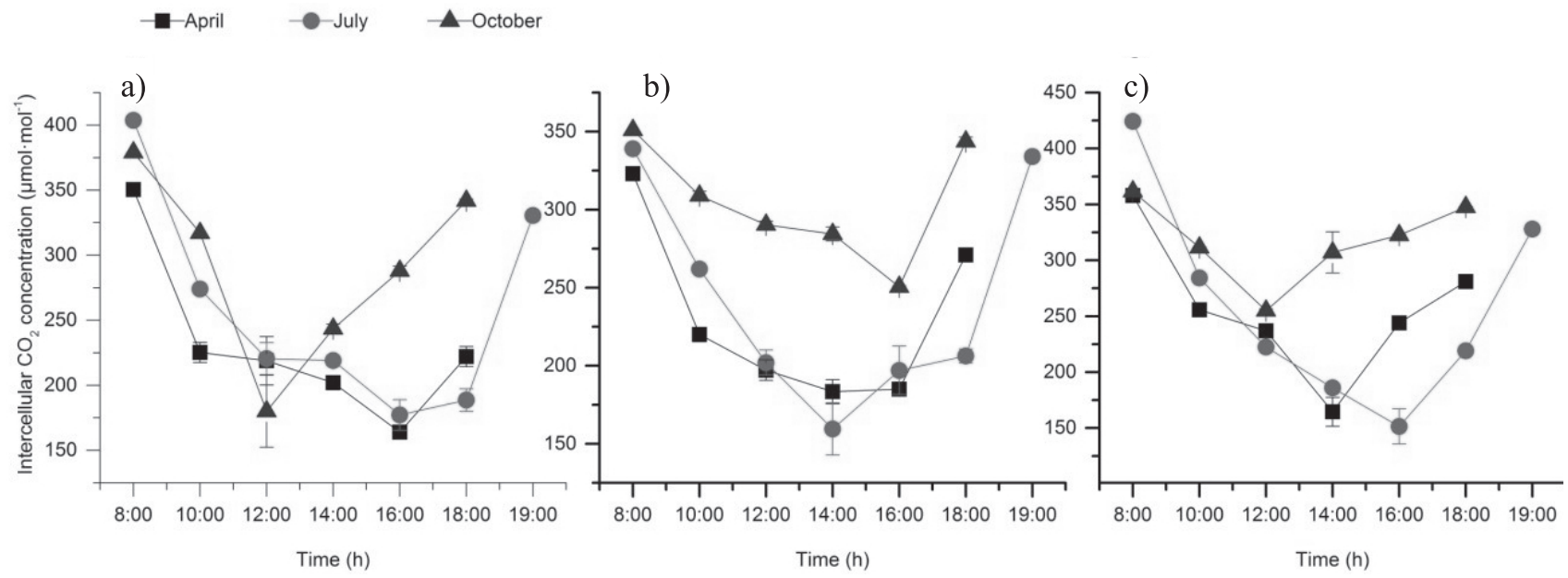

Fig. 6. The characteristics of annual diurnal variation on intercellular $\mathrm{CO}_{2}$ concentration. a) Photosynthetic active radiation, b) Atmospheric temperature, c) Atmospheric pressure.

\section{Correlation Analysis}

From Table 2, in April, the transpiration rate of Trifolium repens, photosynthetic active radiation, and air temperature were highly significantly correlated, and the intercellular $\mathrm{CO}_{2}$ concentration of Trifolium repens was significantly related to air temperature. In July, stomatal conductance was significantly correlated with the intercellular $\mathrm{CO}_{2}$ concentration, and the transpiration rate was highly significantly correlated with the atmospheric pressure, while the intercellular $\mathrm{CO}_{2}$ concentration was significantly correlated with the temperature of the atmosphere. In October, the concentration of $\mathrm{CO}_{2}$ was significantly correlated with the photosynthetically active radiation and the atmospheric temperature and the net photosynthetic rate was significantly correlated with

Table 2. Correlation coefficients of environmental factors and photosynthetic characteristic parameters.

\begin{tabular}{|c|c|c|c|c|c|c|c|}
\hline Species & Parameters & $\mathrm{T}$ & $\mathrm{P}$ & $\mathrm{Ci}$ & $\operatorname{Tr}$ & Gs & Pn \\
\hline \multirow{6}{*}{ Trifolium repens (Apr.) } & PAR & $0.874^{*}$ & 0.441 & -0.734 & $0.947^{* *}$ & 0.122 & 0.727 \\
\hline & $\mathrm{T}$ & 1 & -0.033 & $-0.905^{*}$ & $0.942^{* *}$ & -0.256 & 0.532 \\
\hline & $\mathrm{P}$ & & 1 & 0.201 & 0.264 & 0.789 & 0.539 \\
\hline & $\mathrm{Ci}$ & & & 1 & -0.799 & 0.262 & -0.591 \\
\hline & $\operatorname{Tr}$ & & & & 1 & 0.068 & 0.719 \\
\hline & Gs & & & & & 1 & 0.618 \\
\hline \multirow{6}{*}{ Trifolium repens (Jul.) } & PAR & $0.956^{* *}$ & 0.700 & $0-.689$ & 0.649 & -0.407 & 0.675 \\
\hline & $\mathrm{T}$ & 1 & 0.615 & $-0.775^{*}$ & 0.598 & -0.589 & 0.637 \\
\hline & $\mathrm{P}$ & & 1 & -0.066 & $0.928^{* *}$ & 0.228 & 0.449 \\
\hline & $\mathrm{Ci}$ & & & 1 & -0.135 & $0.785^{*}$ & -0.689 \\
\hline & $\operatorname{Tr}$ & & & & 1 & 0.185 & 0.626 \\
\hline & Gs & & & & & 1 & -0.166 \\
\hline \multirow{6}{*}{ Trifolium repens (Oct.) } & PAR & 0.776 & 0.750 & $-0.829^{*}$ & 0.529 & -0.321 & $0.889^{*}$ \\
\hline & $\mathrm{T}$ & 1 & 0.340 & $-0.915^{*}$ & $0.818^{*}$ & -0.696 & 0.809 \\
\hline & $\mathrm{P}$ & & 1 & -0.320 & 0.397 & 0.152 & $0.817^{*}$ \\
\hline & $\mathrm{Ci}$ & & & 1 & -0.572 & 0.659 & -0.701 \\
\hline & $\mathrm{Tr}$ & & & & 1 & -0.354 & 0.787 \\
\hline & Gs & & & & & 1 & -0.326 \\
\hline
\end{tabular}


Table 2. Continued.

\begin{tabular}{|c|c|c|c|c|c|c|c|}
\hline Species & Parameters & $\mathrm{T}$ & $\mathrm{P}$ & $\mathrm{Ci}$ & $\operatorname{Tr}$ & Gs & $\mathrm{Pn}$ \\
\hline \multirow{6}{*}{ Trifolium pratense (Apr.) } & PAR & $0.888^{*}$ & 0.381 & $-0.904^{*}$ & $0.986^{* *}$ & 0.081 & 0.743 \\
\hline & $\mathrm{T}$ & 1 & -0.066 & $-0.982^{* *}$ & $0.934^{* *}$ & -0.272 & 0.518 \\
\hline & $\mathrm{P}$ & & 1 & -0.051 & 0.271 & $0.863^{*}$ & 0.711 \\
\hline & $\mathrm{Ci}$ & & & 1 & $-0.941^{* *}$ & 0.122 & -0.636 \\
\hline & $\operatorname{Tr}$ & & & & 1 & 0.019 & 0.730 \\
\hline & Gs & & & & & 1 & 0.674 \\
\hline \multirow{6}{*}{ Trifolium pratense (Jul.) } & PAR & $0.963^{* *}$ & 0.527 & $-0.905^{* *}$ & $0.872^{*}$ & -0.236 & $0.848^{*}$ \\
\hline & $\mathrm{T}$ & 1 & 0.452 & $-0.912^{* *}$ & $0.851^{*}$ & -0.364 & $0.821^{*}$ \\
\hline & $\mathrm{P}$ & & 1 & -0.213 & $0.771^{*}$ & 0.606 & 0.736 \\
\hline & $\mathrm{Ci}$ & & & 1 & -0.712 & 0.467 & -0.750 \\
\hline & $\operatorname{Tr}$ & & & & 1 & 0.140 & $0.953^{* *}$ \\
\hline & Gs & & & & & 1 & 0.179 \\
\hline \multirow{6}{*}{ Trifolium pratense (Oct.) } & PAR & $0.856^{*}$ & 0.322 & $-0.859^{*}$ & $0.935^{* *}$ & 0.086 & 0.625 \\
\hline & $\mathrm{T}$ & 1 & 0.052 & -0.803 & $0.920^{* *}$ & -0.349 & 0.156 \\
\hline & $\mathrm{P}$ & & 1 & 0.174 & 0.171 & $0.823^{*}$ & 0.380 \\
\hline & $\mathrm{Ci}$ & & & 1 & -0.809 & 0.245 & -0.552 \\
\hline & $\operatorname{Tr}$ & & & & 1 & -0.186 & 0.364 \\
\hline & Gs & & & & & 1 & 0.613 \\
\hline \multirow{6}{*}{ Trifolium repens (Apr.) } & PAR & 0.767 & 0.477 & -0.735 & 0.803 & 0.066 & 0.772 \\
\hline & $\mathrm{T}$ & 1 & -0.065 & $-0.950^{* *}$ & $0.880^{*}$ & -0.371 & 0.519 \\
\hline & $\mathrm{P}$ & & 1 & -0.063 & 0.113 & 0.761 & 0.668 \\
\hline & $\mathrm{Ci}$ & & & 1 & -0.744 & 0.329 & -0.544 \\
\hline & $\operatorname{Tr}$ & & & & 1 & -0.003 & 0.707 \\
\hline & Gs & & & & & 1 & 0.573 \\
\hline \multirow{6}{*}{ Trifolium repens (Jul.) } & PAR & $0.937^{* *}$ & 0.466 & $-0.805^{*}$ & 0.749 & -0.358 & $0.931^{* *}$ \\
\hline & $\mathrm{T}$ & 1 & 0.445 & $-0.876^{* *}$ & $0.807^{*}$ & -0.525 & $0.960^{* *}$ \\
\hline & $\mathrm{P}$ & & 1 & -0.070 & 0.753 & 0.378 & 0.303 \\
\hline & $\mathrm{Ci}$ & & & 1 & -0.439 & $0.793^{*}$ & $-0.914^{* *}$ \\
\hline & $\operatorname{Tr}$ & & & & 1 & 0.001 & 0.716 \\
\hline & Gs & & & & & 1 & -0.523 \\
\hline \multirow{6}{*}{ Trifolium repens (Oct.) } & PAR & $0.830^{*}$ & 0.681 & -0.802 & 0.770 & -0.309 & 0.469 \\
\hline & $\mathrm{T}$ & 1 & 0.360 & -0.793 & $0.896^{*}$ & -0.779 & -0.031 \\
\hline & $\mathrm{P}$ & & 1 & -0.510 & 0.189 & 0.126 & 0.592 \\
\hline & $\mathrm{Ci}$ & & & 1 & -0.508 & 0.552 & -0.317 \\
\hline & $\operatorname{Tr}$ & & & & 1 & -0.608 & -0.070 \\
\hline & Gs & & & & & 1 & 0.521 \\
\hline
\end{tabular}

"**"Correlation is significant at the lever of 0.05 , and "***"Correlation is significant at the lever of 0.01 . 
the photosynthetically active radiation and atmospheric pressure, while the transpiration rate correlated with the atmospheric temperature significantly.

In April, the transpiration rate of Trifolium pratense was highly significantly related with photosynthetic active radiation, atmospheric temperature, and intercellular $\mathrm{CO}_{2}$ concentration. The intercellular $\mathrm{CO}_{2}$ concentration correlated with photosynthetically active radiation dramatically, while significant correlation with atmospheric temperature extremely. In July, the stomatal conductance and atmospheric pressure were correlated significantly. The net photosynthetic rate correlated with air temperature and photosynthetically active radiation dramatically, and with transpiration rate extremely. The transpiration rate and air temperature, photosynthetic active radiation, and atmospheric pressure were significantly related, while intercellular $\mathrm{CO}_{2}$ concentration has extreme correlation with photosynthetic active radiation and air temperature. In October, the transpiration rate was significantly correlated with air temperature, photosynthetically active radiation, and atmospheric pressure, and the stomatal conductance was significantly correlated with atmospheric pressure, while the photosynthetically active radiation was significantly correlated with intercellular $\mathrm{CO}_{2}$ concentration and atmospheric temperature.

In April, the atmospheric temperature was closely related to the intercellular $\mathrm{CO}_{2}$ concentration of Medicago sativa and transpiration rate. In July, the photosynthetic effective radiation was significantly correlated with the temperature, net photosynthetic rate, and the intercellular $\mathrm{CO}_{2}$ concentration. The atmospheric temperature was correlated with the intercellular $\mathrm{CO}_{2}$ concentration and the net photosynthetic rate closely, and with the transpiration markedly. The intercellular $\mathrm{CO}_{2}$ concentration was significantly correlated with stomatal conductance. In October, photosynthetically active radiation and atmospheric temperature were significantly correlated, as with the air temperature and the transpiration rate.

\section{Conclusion}

The Salaxi Comprehensive Treatment Demonstration Area of Rocky Desertification is located in the subtropical monsoon climate zone, with annual average rainfall of $984.4 \mathrm{~mm}$. But because of the special geological environment of karst, the surface water formed by the rainfall soon leaks into the underground along the fissures and precipitation cannot be stored in the surface. In addition, the thin soil layer, the slow soil formation rate, bare rock, and fast evaporation of surface water make for only a little water being stored in the soil. The special karst geological condition requires that the planted artificial forage has higher water use efficiency, that is to say it has the optimal combination of a high photosynthetic rate and low transpiration rate [27-28].

The curves of the net photosynthetic rate and the annual diurnal variation of transpiration rate for three kinds of experimental pastures showed different trends that were mainly related to test materials. This indicates that there were great differences in net photosynthetic rate and transpiration physiology during different forages, and it also showed great differences of photosynthetic physiological change in different seasons. Through the research of annual photosynthetic physiology among the three kinds of leguminous forage of Trifolium repens, Trifolium pretense, and Medicago sativa it can be concluded that the highest net photosynthetic rate of legume forage was Medicago sativa followed by Trifolium repens, and the lowest was Trifolium pratense. The highest transpiration rate was Trifolium pratense followed by Trifolium repens, and the lowest was Medicago sativa. The difference between them was insignificant. The water use efficiency of Medicago sativa was the highest because of the highest photosynthetic rate and the lowest transpiration rate, followed by Trifolium repens, and the lowest was Trifolium pratense.

The light intensity, air temperature, and net photosynthetic rate of three kinds of herbage were lower in the early morning (8:00). At the time change, the photosynthetically active radiation increased persistently, the temperature and light intensity rose, and the net photosynthetic rate increased. The net photosynthetic rate of Trifolium repens reached a peak at 10:00, followed by a gradual decrease, and then rose again, which illustrated that Trifolium repens took a dormant form of closing their stomata to reduce water loss and material consumption when facing high photosynthetically active radiation and high temperature. The net photosynthetic rate of Trifolium pretense occurred with the phenomenon of photosynthetic "midday depression" except in April, which avoided the high photosynthetically active radiation. The differences of the net photosynthetic rate of Medicago sativa were larger among the three months. This showed that Medicago sativa was sensitive to high photosynthetically active radiation and high temperatures, existing significant differences when took the dormant form of closing their stomata to reduce water loss and material consumption in different months. Nevertheless, Trifolium repens, Trifolium pretense, and Medicago sativa all have the characteristic of sensitivity to high photosynthetically active radiation and high temperature, and then taking a dormant form of closing their stomata to reduce water loss and material consumption.

The diurnal variation curves of water use efficiency of three kinds of legumes forges present different trends, which showed that there were great differences during the same family but of different species [29]. The Medicago sativa was higher than that of Trifolium repens and Trifolium pretense, which illustrated that Medicago sativa can produce more biomass under the same water conditions. The bedrock is exposed and the surface coverage was low in the rocky karst desertification area, which caused the total effective radiation of the rocky desertification area to be higher than that of the forest land. The light intensity was one of the main reasons for accelerating the transpiration of plants. The effective light radiation of karst rocky desertification area was larger, and 
the temperature was higher. The plants generally regulated their own transpiration to reduce the temperature of the tissue to avoid burning. The primary productivity of grassland depended largely on water use efficiency, planting artificial pasture in the karst rocky desertification area, net photosynthetic rate, transpiration rate, and water use efficiency. The measures on equipping different kinds of forages not only reduce the transpiration rate and water loss, but also improve water use efficiency, and ease the current situation of drought and water shortage in rocky desertification areas. From considering the overall perspective of annual photosynthetic physiological characteristics: Medicago sativa is more suitable than Trifolium repens and Trifolium pretense for the habitat conditions in light-moderate karst rocky desertification areas.

\section{Acknowledgements}

We are grateful for support by the National Key Research and Development Program of China in the 13th Five-year Plan: Ecological industry model and integrated technology and demonstration for the rocky desertification control of the karst plateau gorge (2016YFC0502607 and 2016YFC0502601); the Key Project of Science and Technology Program of Guizhou Province: Key technology and demonstration for the State Engineering Technology Institute for Karst Desertification Control (Qian $\mathrm{Ke} \mathrm{He}$ Zhong Da Zhuan Xiang Zi [2014] 6007); the Project of Science and Technology Program of Guizhou Province: Construction for the Provincial Engineering Technology Institute for Karst Desertification Control (Qian Ke He She G Zi [2012] 4008); the Project of Innovation Program for Postgraduate Education of Guizhou Province: Xiong Kangning`s studio of postgraduate supervisors for the karst environment of Guizhou Province (QIANJIAOYANHE GZS ZI [2016]04); and the Project of National Key Innovation Base Construction: Construction of State Engineering Technology Institute for Karst Desertification Control (GUOKEFAJI [2013] 405, 2012FU125X13).

\section{References}

1. GAO J., KANG F., HAN H. Effect of Litter Quality on Leaf-Litter Decomposition in the Context of Home-Field Advantage and Non-Additive Effects in Temperate Forests in China. Pol.J.Environ.Stud, 25 (5), 1911, 2016

2. XIONG K.N., CHI Y.K. The Problems in Southern China Karst Ecosystem in Southern of China and Its Countermeasures. Ecol Economy, 31 (1), 23 , 2015.

3. LIANG Y., CAO R.X. Employment Assistance Policies of Chinese Government Play Positive Roles! The Impact of Post-earthquake Employment Assistance Policies on the Health-related Quality of Life of Chinese Earthquake Populations. Social Indicators Research, 120 (3), 835, 2015.

4. ZENG F.P., WANG K.L. Effects of "Grain-for-Green" Models in Karst Regions in Northwest Guangxi. Rural EcoEnvironment, 21 (2), 18, 2005.
5. MENG J.J, TANG C.B., QIAN X.G., MO B.M., LONG Z.F., ZHAO M.K. An Introduction Test of Alfalfa on the Conversed Cultivating Land in Karst Mountainous Area. Guizhou Agricultural Sciences, 33 (6), 51, 2005.

6. XING Z.X., FANG B.H., YANG Z.J., XIAO R.L. Productivity Analysis of 4 Grasses in Northwestern Guangxi Karst Peak-Cluster Billabong. Pratacultural Science, 24 (12). 48, 2007.

7. YUAN D.X. World Correlation of Karst Ecosystem: Objection and Implementation Plan. Advance in Earth Sciences, 16 (4), 461, 2001.

8. WANG S.J. Concept Deduction and Its Connotation of Karst Rocky Desertification. Carsologica Sinica, 22 (2), 1202003.

9. XIONG K.N., YUAN J.Y., FANG Y.N. Guizhou Karst Rocky Desertification Prevention and Control Atlas. Guiyang, Guizhou People Press, 2006.

10. WEI L.Y., ZENG D.J, ZHANG J.L., YOU Y.M., JIAO J.F., HUANG Y.Q. The Photosynthetic Characteristics of Four Forage Grasses in Karst Rock Desertification Areas. Acta Pratacultural Sinica, 19 (3), $212,2010$.

11. H. AKGUL, C. ERGUL, D. YILMAZKAYA. Diversity of Microfungi on Fagaceae in Uludag Forests. Oxid Commun, 38 (3), 1529, 2015

12. SHI G.F., LI F.Y., WANG G.Y. Antioxidant Activity of Diosgenin from Discorea. Oxid Commun, 39 (1), 91, 2016.

13. LEKISHVILI N., BARBAKADZE K.H., GIGAURI R. Advanced Composites and Materials Based on Natural and Secondary Resources of Caucasus Region and Novel Hybrid Bioactive Compounds. Oxid Commun, 39 (2), 1417, 2016.

14. SZCZEPANIAK W. Evaluating Nitrogen Use Efficiency (NUE) Indices on the Background of Mineral Status of the Seed Crop at Maturity: a Case Study of Maize. Pol.J.Environ. Stud, 25 (5),2129, 2016

15. LIANG Y., WANG X.K. Developing a New Perspective to Study the Health of Survivors of Sichuan Earthquakes in China: a Study on the Effect of Post-Earthquake Rescue Policies on Survivors' Health-Related Quality of Life. Health Research Policy and Systems, 11 (41), 1, 2013.

16. XU H.T., ZHAO F. B., WANG L. Q. Assessment Index of Biological Integrity to Quantity of Rver in Shanghai. Oxid Commun, 39 (2), 1392, 2016.

17. PLUSA M., AUBYA I., Verlaqueb M., LEVAVAASSEUR G. Seasonal Variations in Photosynthetic Irradiance Response Curves of Macrophytes from a Mediterranean coastal Lagoon. Aquatic Botany, 81 (2), 157, 2005.

18. LIANG Y., LU P.Y. Effect of Occupational Mobility and Health Status on Life Satisfaction of Chinese Residents of Different Occupations: Logistic Diagonal Mobility Models Analysis of Cross-sectional Data on Eight Chinese Provinces. International Journal for Equity in Health, 13 (15), 1, 2014.

19. ZHENG S. X., SHANGGUAN Z.P. Photosynthetic Physiological Adaptabilities of Pinus Tabulaeformis and Robinia Pseudoacacia in the Loess Plateau. Chinese Journal of Applied Ecology, 18 (1), 16, 2007.

20. HU S.L., WAN S.M., JIA Z.K., WANG Y. A Study on Photosynthetic Characteristics of Alfalfas Grown for Different Lengths of Time in the Semi-Humid Region of the Loess Plateau. Acta Prataculturae Sinica, 17 (5), 60, 2008.

21. ALSHOAIBI A.A. Photosynthetic Response of Elephant Grass (Pennisetum purpureum) to $\mathrm{NaCl}$ Salinity. Journal of Biological Sciences, 8 (3), 610, 2008.

22. WAN S.M., JIA Z.K., YANG B.P. Relationship between Diurnal Changes of Alfalfa Net Photosynthetic Rate and Environmental Factors. Acta Agrestia Sinica, 17 (1), 27, 2009. 
23. LIANG Y., GUO M.L. Utilization of Health Services and Health-Related Quality of Life Research of Rural-to-Urban Migrants in China: a Cross-Sectional Analysis. Social Indicators Research, 120 (1), 277, 2015.

24. RUBIO F.C., CAMACHO F.G., SEVILLA J.M.F., CHISTI Y., GRIMA E.M. A Mechanistic Model of Photosynthesis in Micro Algae. Biotechnology and Bioengineering, 81 (4), 459, 2003.

25. ZHENG S.X., SHANGGUAN Z.P. Comparison of Leaf Gas Exchange and Chlorophyll Fluorescence Parameters in Eight Broad-Leaved Tree Species. Acta Ecologica Sinica, 26 (4), 1080, 2006.

26. CHI Y.K., XIONG K.N., ZHANG J.H. Study on the Photosynthetic Rate and Water Use Efficiency of 3
Leguminous Grass Species in Karst Rocky Desertification Area. Chinese Journal of Grassland, 36 (4), 116, 2014.

27. CHI Y.K. Technology and Demonstration on Spatial Optimal Allocation of Agricultural-Grass and Forest-grass in the Karst Desertification Control. Guiyang, Guizhou Normal University, 2015.

28. CHI Y.K., XIONG K.N., ZHANG Z.Z. Research on Photosynthetic Interannual Dynamics of Gramineous Forage in the Karst Rocky Desertification Regions of South China. Oxid Commun, 39 (3-I), 2476, 2016.

29. QIN X.J., SUN J., LIU M., LU X.Y. The Impact of Climate Change and Human Activity on Net Primary Production in Tibe. Pol.J.Environ.Stud, 25 (5), 2113, 2016. 